\title{
Keep Calm and Go Abroad: The Effect of Learning Abroad on Student Mental Health
}

\section{Amber Bathke, Ryoka Kim \\ University of Minnesota - Twin Cities}

In the spring of 2015 , about $25 \%$ of US undergraduate students reported suffering from a mental health condition within the last 12 months (American College Health Association, 2015, p. 15). This number includes only students who were diagnosed or treated by a professional for such conditions. The percentage is undoubtedly higher when including those who did not seek assessment or treatment. In fact, almost $57 \%$ of students reported experiencing overwhelming anxiety within the last year, and $34 \%$ reported feeling so depressed it was difficult to function (p. 14). Suffice it to say that mental health is a significant concern on US college campuses. But what happens when those campuses go global?

It stands to reason that the percentage of students facing mental health concerns while abroad would be at least equal to the percentage on campus. The experience of those of us who work in the international education field suggests that the percentage may be even higher than on campus, since culture shock, homesickness, and stress can trigger anxiety, depression, or other mental health conditions, especially in students who have struggled previously with such concerns. But do statistics support this anecdotal evidence? How does mental health during study abroad vary across populations? Very little empirical data exist to guide us on this subject. Therefore, the Learning Abroad Center and University Counseling and Consulting Services at the University of Minnesota - Twin Cities conducted a research project to determine the following:

- An overall picture of student mental health while abroad

- Percentage of students studying abroad who reported experiencing a diagnosed mental health condition while abroad

- The nature of these diagnosed mental health conditions

- Frequency of relapse/recurrence of existing conditions while abroad

- Frequency and type of treatment received

- Local attitude toward mental health conditions

\section{Review of the Literature}

There exists very little literature dealing specifically with the mental health of US college students studying abroad. Most of the existing literature takes the form of best practices guides for educators. There is also a significant body of research dealing specifically with one specific mental health concern 
or symptom — student alcohol use-as well as a number of studies relating to the mental health of international students in general.

\section{Guides for Educators.}

There are a great many guides and resources dedicated to helping student service professionals identify and aid a student with mental health concerns, but these are typically very heavy on advice and techniques and contain very little, if any, statistical data. For example, NAFSA's Crisis Management in a Cross-Cultural Setting contains a chapter on mental health, which serves as an exhaustive guide for international educators on best practices for handling student mental health concerns, pre-departure through re-entry (Burak \& Hoffa, 2001).

The Jed Foundation's "Depression and Suicidal Behaviors in Students Studying Abroad: Identifying Students at Risk" (n.d.) contains information on the symptoms of culture shock, clinical depression and mania, the warning signs, and how to approach a student and help them seek medical attention. These resources for educators are extremely useful, but do not provide any concrete data.

Mobility International USA and the Center for Global Education take a slightly different tack, publishing resources geared toward students themselves on maintaining good mental health while abroad, but while these resources are extremely helpful and a great resource for students, neither provide any concrete statistics.

\section{Student Alcohol Use While Abroad}

A great deal of research exists on the specific issue of alcohol use and abuse, which is considered a behavior indicative of mental health concerns, by students studying abroad. The Healthy Minds Study reports a strong correlation between Major Depressive Disorder (MDD) and Heavy Episodic Drinking (HED), which is defined as the consumption of four and five drinks in a row for females and males, respectively. An in-depth analysis by Dr. Paola Pedrelli confirms that "MDD and HED are highly correlated in undergraduate populations, and that students with severe depressive symptoms... are significantly more likely to engage in HED than those with low/no depressive symptom." (Healthy Minds, 2014, p.1). In addition, "Not only do students with depressive symptoms engage in HED more frequently, they also consume more alcohol per HED episode than their nondepressed peers (Healthy Minds, 2014, p.1)." The Healthy Minds Survey also indicates that of the general undergraduate population, "approximately 10\% of undergraduates screen positive for MDD (as measured by Patient Health Questionnaire-9) and nearly 50\% report episodes of HED in the past two weeks" (Healthy Minds, 2014, p.1).

Much of the current research on student alcohol use while abroad is that of Pederson, LaBrie and Hummer, along with several other researchers. Pedersen, LaBrie and Hummer (2009) report on research in which they surveyed 91 students planning to study abroad about pre-abroad drinking, perceptions of student drinking while abroad, and intentions to drink while abroad. This study found that students' intentions and perceptions of drinking before going abroad correlated with drinking behavior while abroad, but that students actually drank more than they thought they would while abroad.

In a subsequent article, Hummer, Pedersen, Mirza and LaBrie (2010) discuss the consequences of student drinking while abroad. Among other things, they found that the frequency of student 
drinking increased significantly from pre-departure levels, but the number of drinks per occasion stayed about the same. The increased frequency can be explained by various factors, such as the role of alcohol in the culture of some countries, and increased accessibility of alcohol due to lower drinking ages.

Finally, Pedersen, LaBrie, Hummer, Larimer and Lee (2010) theorize that students with already heavier drinking habits may self-select into study abroad, with the intention of drinking while abroad. The results of a survey of 2144 students revealed, "participants with no intention to study abroad drank less and experienced fewer alcohol-related consequences than participants intending to study abroad" (p.1). This could be explained by a variety of factors, but self-selection does constitute a possible explanation. However, the results of this study also determined that students who had already studied abroad drank more than those not intending to study abroad. These findings were not borne out in our study, which we will discuss later.

\section{General Mental Health of International Students}

A large body of work exists on the mental health of international students studying in the U.S. Although the general experiences of international students in the U.S. may be similar to that of some U.S. students studying abroad, it is important to note that students from other countries do not typically "study abroad" in the same way that U.S. students do. While the majority of U.S. students studying abroad do so on a program with other U.S. students, dedicated onsite support, and often even a faculty member accompanying the group, most international students from other countries are either full-degree seeking or exchange students. There is typically much less of a cohort model and less dedicated support, as well as a greater chance of being the only student from their home institution (or even country) at their host institution. There is also often more of a language barrier, as study abroad programs for U.S. students in other countries frequently offer coursework in English, while U.S. universities almost never offer coursework in an international student's native language. However, a sampling of such studies is useful as background information.

Sam and Eide (1991) surveyed the mental health of foreign students before and during their time abroad. Three hundred and ten international students at the University of Bergen, Norway, completed two questionnaires that were developed for the study: an Adjustment and Health Inventory (AHI) and a Symptom Checklist (SL). The results indicate that international students often struggle with loneliness, tiredness, sadness and worrying, and report a higher rate of anxiety, depression, paranoia and somatic complaints while abroad compared to native students.

Sümer, Poyrazli and Grahame (2008) examined the predictors of international students' depression and anxiety levels. Participants were 440 international college students studying in the U.S. The following questionnaires as well as a demographic survey were administered: The Goldberg Depression Scale (GDS), the State Anxiety Scale of the State-Trait Anxiety Inventory (STAI), and the Social Provisions Scale (SPS). Results indicate that poor social support and English proficiency are associated with higher levels of depression and anxiety. Older participants are more vulnerable to anxiety, which may be due to the negative correlation between the participants' age and English proficiency as well as socialization with native students. Results also suggest that gender or length of stay are not significantly related to levels of depression or anxiety as the previous studies indicated. 
Moores and Popadiuk (2011) take a slightly different tack, looking at international student mental health through a lens of positive psychology. Their study looked at the experience of seven international students (four from China, one from Honduras, one from Argentina, and one from Denmark) studying at a Canadian university. They found that although it is true that international students face many challenges while abroad, "despite the prevailing negative depiction [of international student mental health], many international students manage these challenges well" (p. 292). Through interviews focusing on 134 experiences and events described by the participants, using the Critical Incident Technique (CIT) methodology, Moores and Popadiuk identified four broad themes for facilitating cross-cultural transition: connecting with others, maintaining a foundation (preserving identity, support from family and friends at home, etc.) embracing the process, and discovering strengths within. The results of the study provided "compelling support for the application of a positive psychology approach to the topic of cross-cultural transition" (p.302). The results of the present study also support this idea, suggesting that positive psychology could also be an effective lens through which to examine the experiences of American students studying abroad.

\section{American Students Studying Abroad}

Hunley (2009) conducted one of the few studies focusing specifically on the mental health of US students studying abroad. The longitudinal study investigated whether psychological distress and loneliness are connected to deteriorated functioning during study abroad. Sixty-six American students who were studying at Loyola University in Rome participated to the first study. They completed a series of questionnaires at two points: before departure of their home country and during the fourth week of the semester in Rome. The questionnaires are the Functioning of Students Abroad Questionnaire (FOSA), the Beck Anxiety Inventory (BAI), the Depression Adjective Checklist (DACL), and the revised UCLA Loneliness Scale. For the second study, 46 American students attending Loyola University in Rome completed the FOSA, BAI, Revised UCLA Loneliness Scale, and the Beck Depression Inventory II (BDI-II) at three points over the course of 14 weeks during their stay. Results indicate that students experienced more psychological distress and loneliness than they did in their home country, which may deteriorate their performance as a student. However, results also show that positive coping skills and active engagement in their education alleviate the distress.

\section{Methodology}

Procedure

The research was conducted by means of an online survey administered by the University of Minnesota's Office of Measurement Services. A link to the survey was sent via email. Identification information was stripped before the results were sent to the researchers in order to maintain participant anonymity.

\section{Participants}

The survey pool consisted of people who had participated in study abroad through the Learning Abroad Center between Summer 2009 and Spring 2012, a total of 7,191 students. We received 613 responses for a response rate of $8.52 \%$. While this response rate is low, there are several factors that could contribute to the low response rate. First, the survey included people who had studied abroad up to three years before the survey was sent out. Email addresses may have changed, or students may have graduated and stopped checking university email. Additionally, the length of time elapsed 
between studying abroad and the survey may have negatively impacted people's interest in participating in the survey.

Consistent with overall study abroad participation data, participants consisted of $75.5 \%$ females, $22.7 \%$ males, and $1.8 \%$ of students choosing not to disclose their sex.

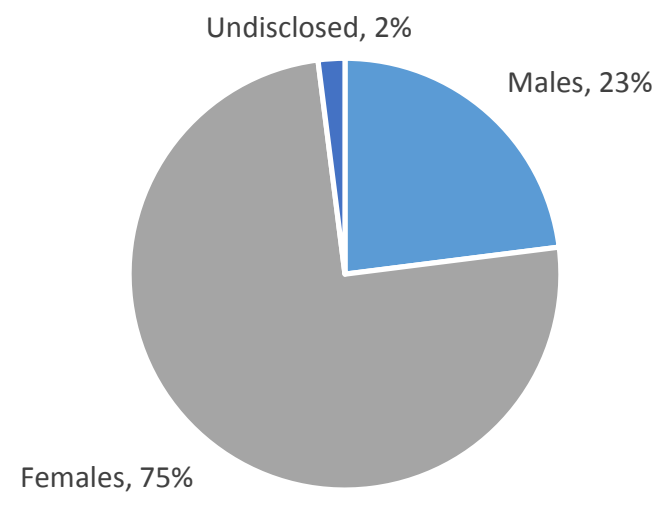

\section{Figure 1. Sex of Survey Participants}

Students who had studied abroad as freshmen made up $1.8 \%$ of the respondents, $16.2 \%$ were sophomores when they went abroad, $48.3 \%$ were juniors, and $21.5 \%$ were seniors. Graduate students and participants selecting "Other" (non-students, etc.) made up $9.6 \%$ and $2.3 \%$ of the respondents, respectively.

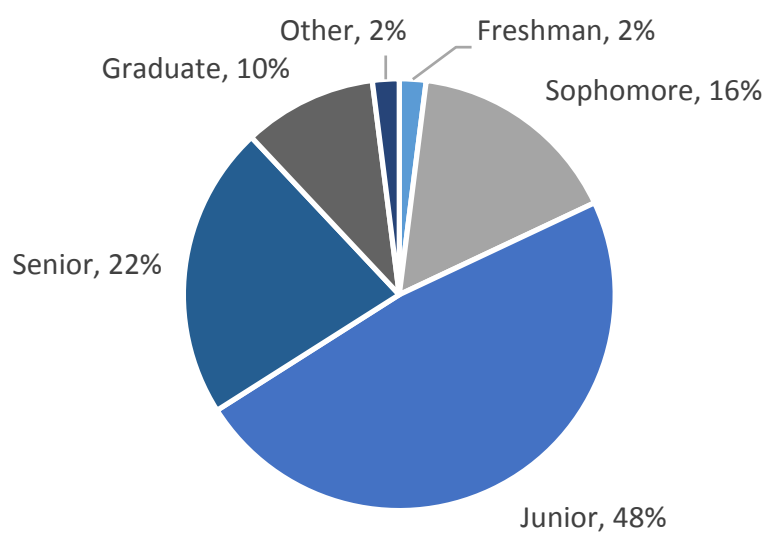

Figure 2. Year in School during Study Abroad 


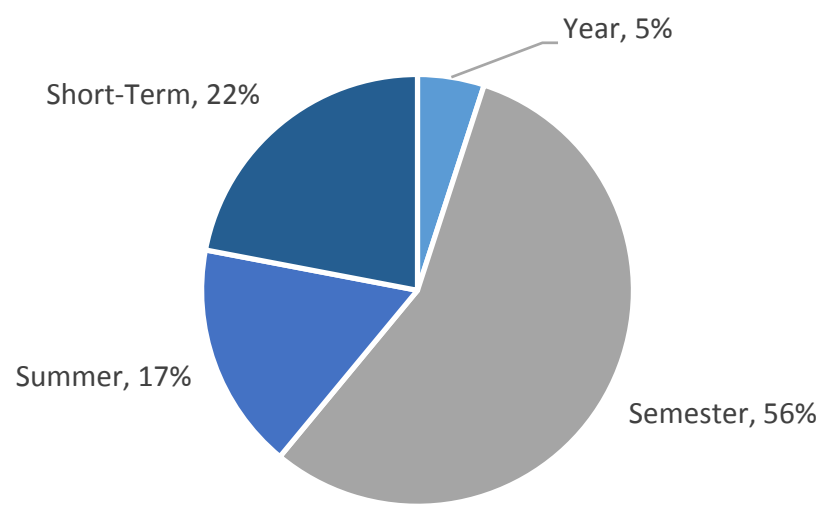

Figure 3. Length of Program

$22 \%$ of respondents participated in a short-term program, defined as three weeks or less. Summer participants made up $17.1 \%$ of the respondents, while $56.3 \%$ of students did a semester-long program and $4.6 \%$ studied abroad for a full year.

Students who studied in the Americas made up $17.8 \%$ of the respondents, $52.5 \%$ studied in Europe, $8 \%$ in Asia, $14.5 \%$ in Africa and the Middle East, and $6.4 \%$ in Oceania.

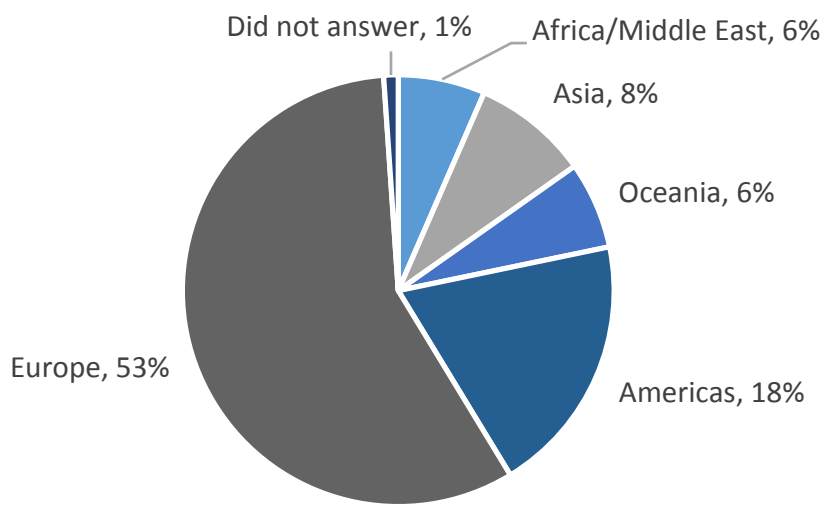

Figure 4. Region

Faculty-led program participants made up $22.2 \%$ of the respondents, $3.6 \%$ did non-credit work, intern, volunteer, or teaching programs, $40.8 \%$ participated in a study center program (most classes are with other U.S. or international students on the program), $11.4 \%$ on a hybrid program (defined as having a combination of study center and host university classes), and $21.7 \%$ participated in an exchange or host university study program (most classes are at a local university with students and faculty from the host country). 


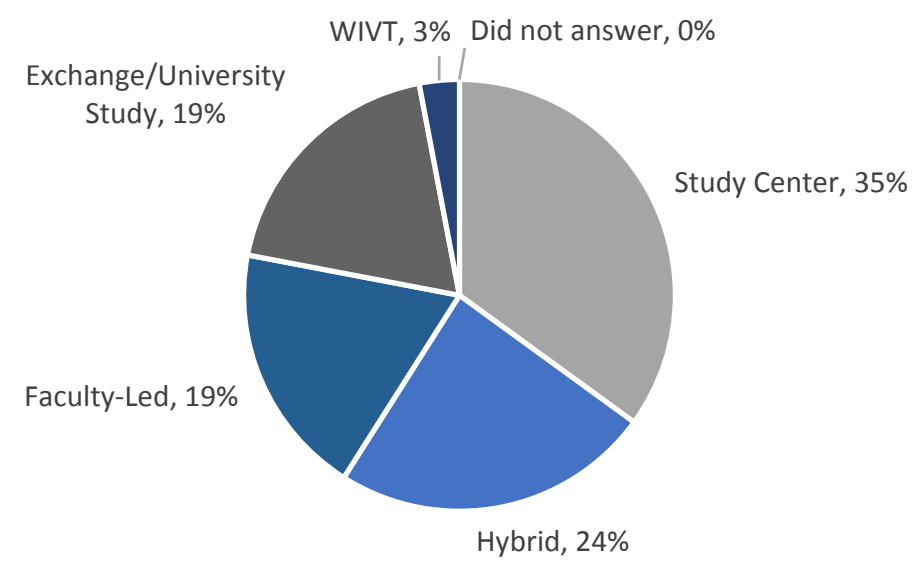

Figure 5. Program Type

\section{Measures}

In addition to supplying their sex, their year in school when they went abroad, the type and length of program, and the region of program location, participants complete a modified version of the Behavioral Health Measure-20, or BHM-20 (Kopta \& Lowry, 2002). This measure is a self-reported survey that uses questions answered on a 5-point Likert scale to assess the three phases of behavioral health: Well-Being, Psychological Symptoms, and Life Functioning. Questions on diagnosed mental health conditions were answered on a yes or no basis, with open-ended questions for further elaboration.

\section{Results \& Discussion}

\section{Overall picture of student mental health while abroad (BHM Results)}

Overall, students reported good mental health while abroad. On questions dealing with overall well-being during study abroad, over $80 \%$ of students indicated agreement with statements claiming emotional health, satisfaction with life, motivation and energy, physical health, and satisfaction with academic performance. The percentage of affirmative answers on the question about belonging was slightly lower, with $68.84 \%$ of students selecting 'Agree' or 'Strongly Agree.' This is not surprising, as living in a country and culture other than one's own can certainly cause one to feel 'apart' in some way. Most students $(72.10 \%)$ of students selected 'Disagree' or 'Strongly Disagree' when asked whether their life caused them to feel distressed.

The questions about life functioning during study abroad yielded slightly lower percentages of students reporting good mental health, but still indicate that for the majority (average 75.17\%) of students, their mental health did not interfere with relationships, school, life enjoyment, cultural adjustment, or friendships. 
Table 1. General Well-Being During Study Abroad

\begin{tabular}{|l|l|l|l|l|l|l|l|}
\hline & $\begin{array}{l}\text { My life } \\
\text { caused me } \\
\text { to feel } \\
\text { distressed. }\end{array}$ & $\begin{array}{l}\text { I was } \\
\text { emotionally } \\
\text { healthy. }\end{array}$ & $\begin{array}{l}\text { I was } \\
\text { satisfied } \\
\text { with my life. }\end{array}$ & $\begin{array}{l}\text { In general, I } \\
\text { felt motivated } \\
\text { and energetic. }\end{array}$ & $\begin{array}{l}\text { I felt like I } \\
\text { 'belonged.' }\end{array}$ & $\begin{array}{l}\text { Overall, I } \\
\text { was } \\
\text { physically } \\
\text { healthy. }\end{array}$ & $\begin{array}{l}\text { I was } \\
\text { generally } \\
\text { satisfied with } \\
\text { my academic } \\
\text { performance. }\end{array}$ \\
\hline Strongly disagree & $36.70 \%$ & $2.28 \%$ & $1.14 \%$ & $0.49 \%$ & $2.45 \%$ & $0.82 \%$ & $0.82 \%$ \\
\hline Disagree & $35.40 \%$ & $6.36 \%$ & $4.57 \%$ & $5.87 \%$ & $10.93 \%$ & $7.67 \%$ & $5.87 \%$ \\
\hline Neutral & $10.77 \%$ & $8.81 \%$ & $5.55 \%$ & $7.01 \%$ & $17.29 \%$ & $9.95 \%$ & $8.32 \%$ \\
\hline Agree & $14.36 \%$ & $46.17 \%$ & $40.46 \%$ & $41.11 \%$ & $43.72 \%$ & $45.19 \%$ & $45.51 \%$ \\
\hline Strongly agree & $2.77 \%$ & $36.22 \%$ & $48.29 \%$ & $44.86 \%$ & $25.12 \%$ & $36.22 \%$ & $39.15 \%$ \\
\hline Not Answered & $0.00 \%$ & $0.16 \%$ & $0.00 \%$ & $0.65 \%$ & $0.49 \%$ & $0.16 \%$ & $0.33 \%$ \\
\hline
\end{tabular}

Table 2. Life Functioning During Study Abroad

\begin{tabular}{|l|l|l|l|l|l|}
\hline & Relationships & School & $\begin{array}{l}\text { Life } \\
\text { enjoyment }\end{array}$ & $\begin{array}{l}\text { Cultural } \\
\text { adjustment }\end{array}$ & Friendships \\
\hline Never & $48.94 \%$ & $52.69 \%$ & $49.59 \%$ & $49.59 \%$ & $50.73 \%$ \\
\hline Rarely & $25.12 \%$ & $24.96 \%$ & $21.21 \%$ & $27.73 \%$ & $25.29 \%$ \\
\hline Sometimes & $16.64 \%$ & $13.70 \%$ & $18.43 \%$ & $15.33 \%$ & $15.82 \%$ \\
\hline Often & $7.99 \%$ & $7.18 \%$ & $8.48 \%$ & $5.87 \%$ & $6.36 \%$ \\
\hline Always & $1.31 \%$ & $1.47 \%$ & $1.96 \%$ & $1.31 \%$ & $1.47 \%$ \\
\hline Not answered & $0.00 \%$ & $0.00 \%$ & $0.33 \%$ & $0.16 \%$ & $0.33 \%$ \\
\hline
\end{tabular}

Questions about symptoms and behaviors relating to mental health yielded more mixed results. While students answering negatively ('Rarely' or 'Almost Never') when asked about experiencing symptoms such as stress, loneliness, and lack of motivation, still made up the largest percentages, the margin was much smaller than on previous questions. For example, only $40.78 \%$ of students reported rarely or almost never feeling stressed while abroad, while $44.05 \%$ reported feeling stressed sometimes, and $14.85 \%$ reported often or almost always feeling stressed. The question on loneliness $/ \mathrm{missing}$ people from home also yielded fairly high percentages $(22.51 \%$ in total) of affirmative ('Often' or 'Almost Always') answers. On the same question, 36.70\% of students reported sometimes feeling lonely and/or missing people from home, while $40.46 \%$ reported rarely or almost never experiencing such feelings. Questions on moodiness, lack of motivation, feeling overwhelmed, and anxiety yielded slightly higher percentages of negative ('Rarely' or 'Almost Never') responses, ranging from 58.56\% to $71.29 \%$. When asked how often they felt depressed while abroad, $80.59 \%$ of students reported rarely or almost never feeling depressed, $12.40 \%$ answered 'Sometimes,' and only $6.20 \%$ reported feeling depressed often or almost always.

Questions on behaviors related to mental health were also indicative of good mental health, overall. With the exception of alcohol use and self-consciousness, students answering in the negative ('Rarely' or 'Almost Never') when asked how often they engaged in or experienced these behaviors were in the majority (see Table 3). Notably, $93.80 \%$ of students reported rarely or almost never using drugs while abroad, and $97.72 \%$ of students reported rarely or almost never experiencing suicidal thoughts. When asked about alcohol use, $34.75 \%$ of students reported rarely or almost never using 
alcohol while abroad, while 34.91\% indicated that they sometimes drank alcohol, and $30.02 \%$ admitted to frequent drinking. It is not surprising that about half of students reported experiencing homesickness, culture shock and self-conscious at least sometimes.

Table 3. Mental Health Symptoms and Indicative Behaviors during Study Abroad

\begin{tabular}{|l|l|l|l|l|l|l|l|}
\cline { 3 - 9 } \multicolumn{1}{c|}{} & \multicolumn{2}{|l|}{ Symptoms } & Leliness / \\
\cline { 2 - 9 } & Stress & $\begin{array}{l}\text { Loneling } \\
\text { missing } \\
\text { people from } \\
\text { home }\end{array}$ & $\begin{array}{l}\text { Moodi- } \\
\text { ness }\end{array}$ & $\begin{array}{l}\text { Lack of } \\
\text { motivation }\end{array}$ & $\begin{array}{l}\text { Feeling } \\
\text { over- } \\
\text { whelmed }\end{array}$ & Anxiety & Depression \\
\hline Almost Never & $13.38 \%$ & $13.87 \%$ & $31.97 \%$ & $30.18 \%$ & $22.51 \%$ & $34.09 \%$ & $57.26 \%$ \\
\hline Rarely & $27.41 \%$ & $26.59 \%$ & $39.31 \%$ & $35.73 \%$ & $36.05 \%$ & $31.81 \%$ & $23.33 \%$ \\
\hline Sometimes & $44.05 \%$ & $36.70 \%$ & $23.16 \%$ & $24.47 \%$ & $28.55 \%$ & $21.37 \%$ & $12.40 \%$ \\
\hline Often & $12.89 \%$ & $18.76 \%$ & $4.73 \%$ & $7.83 \%$ & $9.95 \%$ & $10.44 \%$ & $4.57 \%$ \\
\hline Almost Always & $1.96 \%$ & $3.75 \%$ & $0.16 \%$ & $1.31 \%$ & $2.28 \%$ & $1.79 \%$ & $1.63 \%$ \\
\hline (Not Answered) & $0.33 \%$ & $0.33 \%$ & $0.65 \%$ & $0.49 \%$ & $0.65 \%$ & $0.49 \%$ & $0.82 \%$ \\
\hline
\end{tabular}

\begin{tabular}{|l|l|l|l|l|l|l|l|}
\hline $\begin{array}{l}\text { Combined } \\
\text { categories }\end{array}$ & \multicolumn{1}{|c|}{} \\
\hline Rarely/never & $40.78 \%$ & $40.46 \%$ & $71.29 \%$ & $65.91 \%$ & $58.56 \%$ & $65.91 \%$ & $80.59 \%$ \\
\hline Sometimes & $44.05 \%$ & $36.70 \%$ & $23.16 \%$ & $24.47 \%$ & $28.55 \%$ & $21.37 \%$ & $12.40 \%$ \\
\hline Often/always & $14.85 \%$ & $22.51 \%$ & $4.89 \%$ & $9.14 \%$ & $12.23 \%$ & $12.23 \%$ & $6.20 \%$ \\
\hline
\end{tabular}

\begin{tabular}{|c|c|c|c|c|c|c|c|}
\hline & \multicolumn{7}{|c|}{ Behaviors } \\
\hline & $\begin{array}{l}\text { Alcohol } \\
\text { use }\end{array}$ & Drug use & $\begin{array}{l}\text { Suicidal } \\
\text { thoughts }\end{array}$ & $\begin{array}{l}\text { Homesick- } \\
\text { ness }\end{array}$ & $\begin{array}{l}\text { Culture } \\
\text { shock }\end{array}$ & $\begin{array}{l}\text { Self- } \\
\text { conscious- } \\
\text { ness }\end{array}$ & Withdrawal \\
\hline Almost Never & $18.92 \%$ & $86.13 \%$ & $95.11 \%$ & $26.59 \%$ & $19.90 \%$ & $21.21 \%$ & $60.20 \%$ \\
\hline Rarely & $15.82 \%$ & $7.67 \%$ & $2.61 \%$ & $26.10 \%$ & $31.32 \%$ & $26.75 \%$ & $23.33 \%$ \\
\hline Sometimes & $34.91 \%$ & $4.24 \%$ & $1.63 \%$ & $32.46 \%$ & $34.75 \%$ & $32.95 \%$ & $11.26 \%$ \\
\hline Often & $25.61 \%$ & $1.14 \%$ & $0.16 \%$ & $11.91 \%$ & $10.93 \%$ & $15.33 \%$ & $4.40 \%$ \\
\hline Almost Always & $4.40 \%$ & $0.49 \%$ & $0.00 \%$ & $2.61 \%$ & $2.28 \%$ & $3.26 \%$ & $0.49 \%$ \\
\hline (Not Answered) & $0.33 \%$ & $0.33 \%$ & $0.49 \%$ & $0.33 \%$ & $0.82 \%$ & $0.49 \%$ & $0.33 \%$ \\
\hline
\end{tabular}

\begin{tabular}{|l|l|l|l|l|l|l|l|}
\hline $\begin{array}{l}\text { Combined } \\
\text { categories }\end{array}$ & \multicolumn{1}{|c|}{ (1) } \\
\hline Rarely/never & $34.74 \%$ & $93.80 \%$ & $97.72 \%$ & $52.69 \%$ & $51.22 \%$ & $47.96 \%$ & $83.52 \%$ \\
\hline Sometimes & $15.82 \%$ & $4.24 \%$ & $1.63 \%$ & $32.46 \%$ & $34.75 \%$ & $32.95 \%$ & $11.26 \%$ \\
\hline Often/always & $30.01 \%$ & $1.63 \%$ & $0.16 \%$ & $14.52 \%$ & $13.21 \%$ & $18.60 \%$ & $4.89 \%$ \\
\hline
\end{tabular}

Although students did indicate some challenges while abroad, most of these challenges (such as homesickness, stress, and culture shock) are normal and expected during an experience abroad and are not necessarily indicative of poor mental health. 


\section{Before-During-After Comparison}

Some interesting patterns emerge when from students' responses to the symptoms and behaviors questions before, during and after study abroad. Students reported experiencing some symptoms and behaviors fairly consistently across all three time periods (notably alcohol use, drug use, and suicidal thoughts). Participants reported a significant increase in some symptoms and behaviors (notably loneliness/missing people from home, homesickness, and culture shock) while abroad, but postabroad these levels fell back off. It is interesting to note, however, that homesickness and culture shock levels, although they did decrease post-abroad relative to during the abroad period, they did not quite go back down to pre-abroad levels. This may indicate a certain degree of reverse culture shock and "homesickness" for the host country (Figures 6-8).

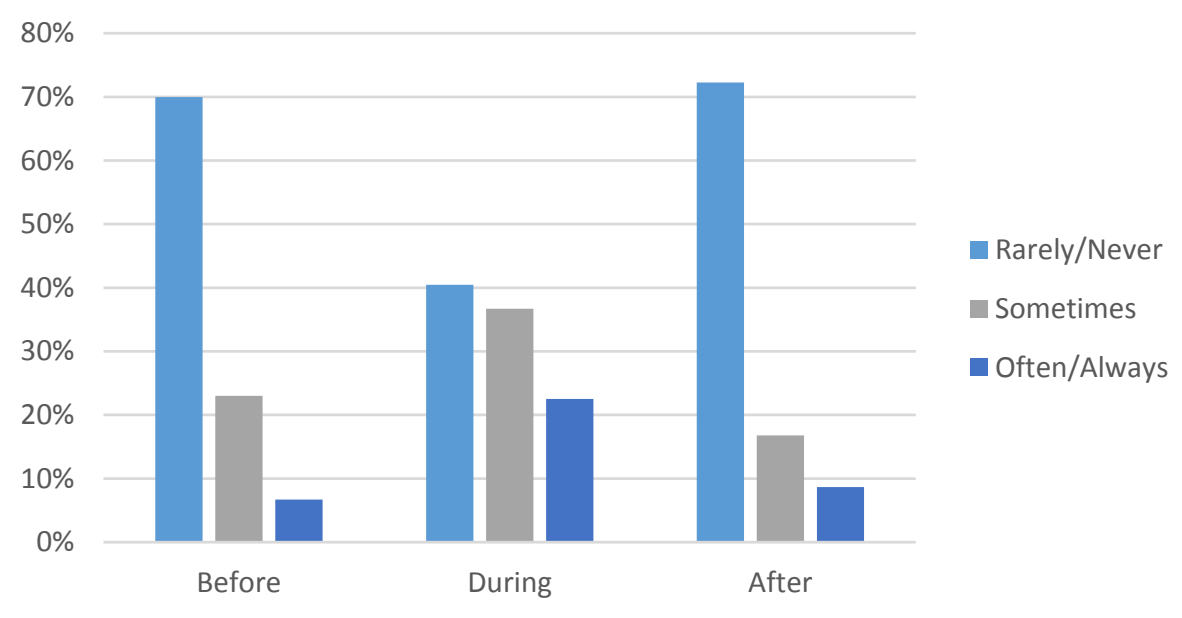

Figure 6. Loneliness/Missing People from Home Before, During and After Study Abroad

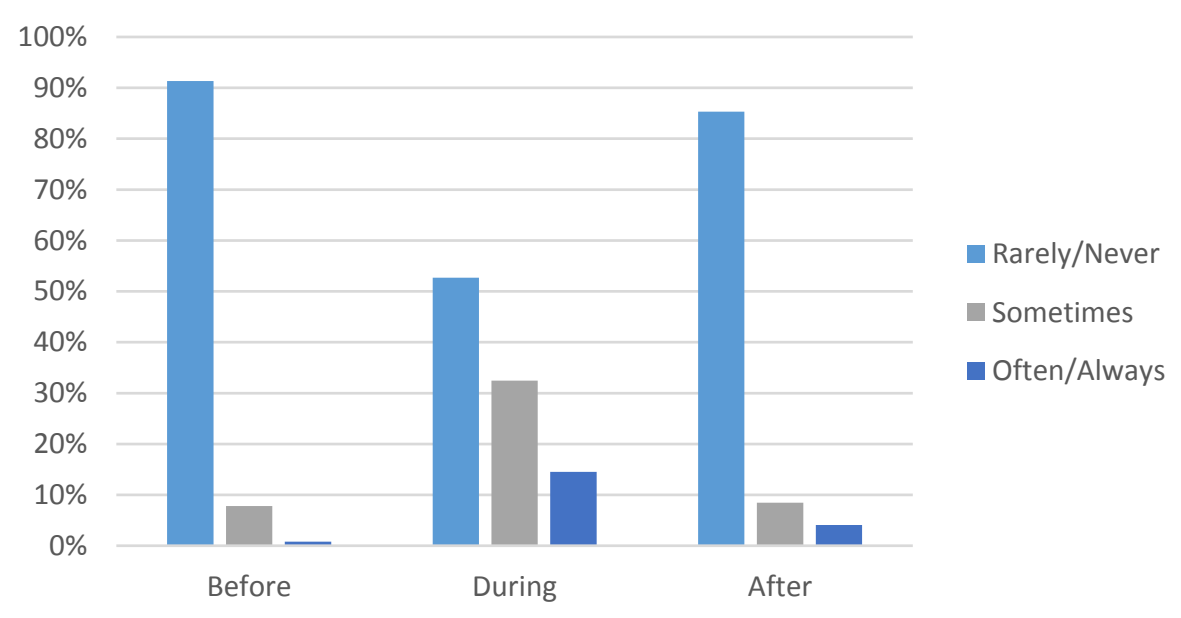

Figure 7. Homesickness Before, During and After Study Abroad 


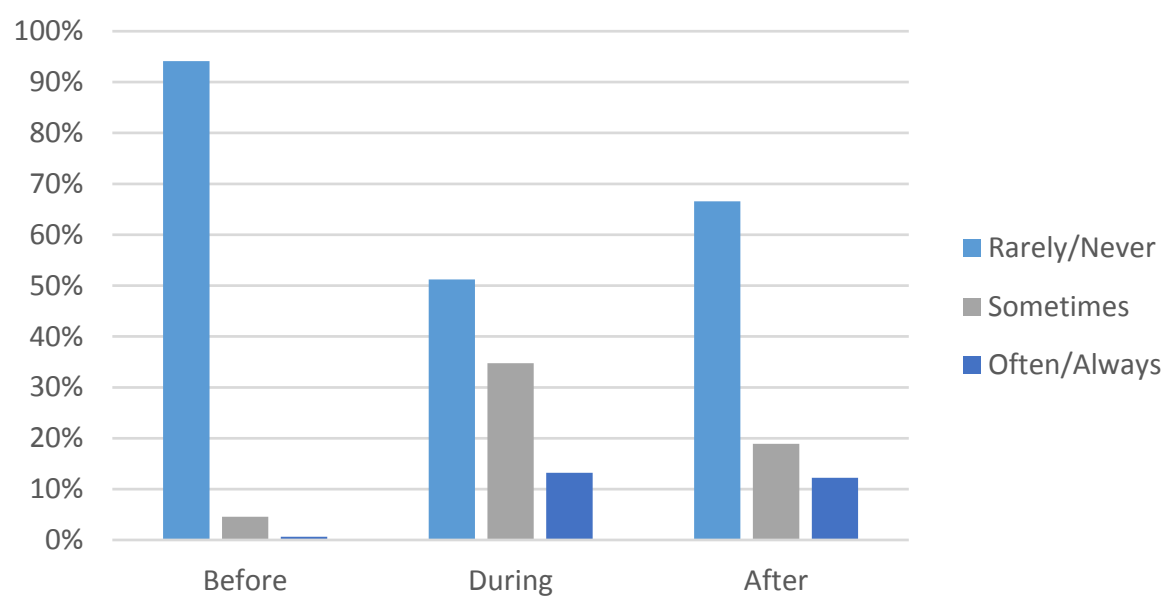

Figure 8. Culture Shock Before, During and After Study Abroad

Encouragingly, studying abroad seemed to improve mental health in some areas. For example, $45.02 \%$ of participants reported feeling stressed often or almost always before their study abroad experience. One might hypothesize that learning to adjust to a new environment and culture might cause stress to increase while abroad, but the data in this study did not show that to be the case. In fact, the percentage of participants reported feeling stress often or almost always dropped to 14.85\% during the abroad period, perhaps reflecting, rather the tendency of many students to think of their study abroad experience as a "vacation." The data regarding the post-study abroad period, however, is quite interesting: Compared to $45.02 \%$ of participants reporting frequent stress prior to going abroad, only $23.00 \%$ of participants reported frequent stress after going abroad. The questions on feeling overwhelmed and anxiety yield similar results. The percentage of participants reporting frequent stress before abroad (28.71\%) dropped during the study abroad period (12.23\%) and although stress levels went back up post-abroad $(21.04 \%)$, they did not quite reach the pre-abroad levels. The percentage of participants reporting rarely or almost never suffering from anxiety preabroad (46.82\%) rose during the abroad period (65.91\%) and went down (57.26\%) post-abroad, but the post-abroad percentage of students suffering infrequently from anxiety remained quite a bit higher than pre-abroad. Self-consciousness followed a slightly different, but still encouraging pattern: 47.31\% of participants reported feeling self-conscious often or almost never. This level remained nearly the same during the abroad period, but post-abroad, the percentage of students reporting infrequent selfconsciousness rose by $10 \%$ to $57.42 \%$. These results may be a reflection of confidence, coping and problem-solving skills gained while abroad that then carry over to students' lives upon return (Figures 9-11). 


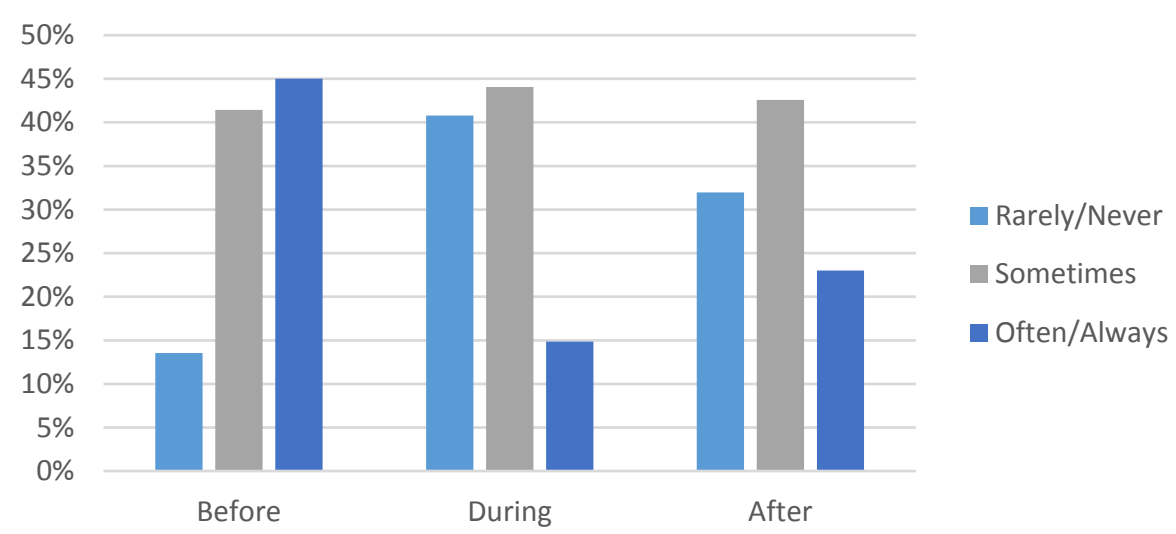

Figure 9. Stress Before, During, and After Study Abroad

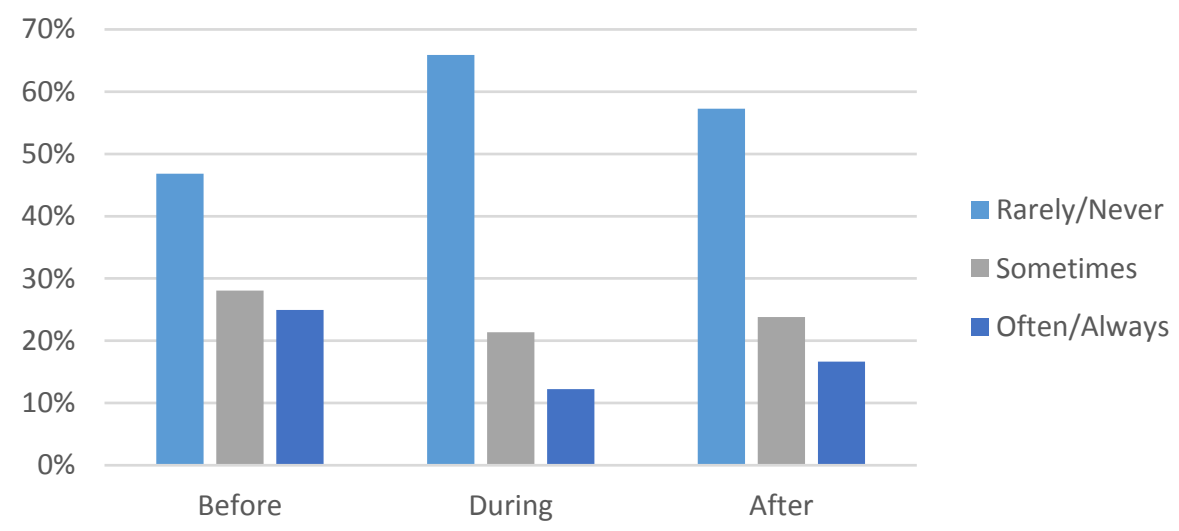

Figure 10. Anxiety Before, During and After Study Abroad

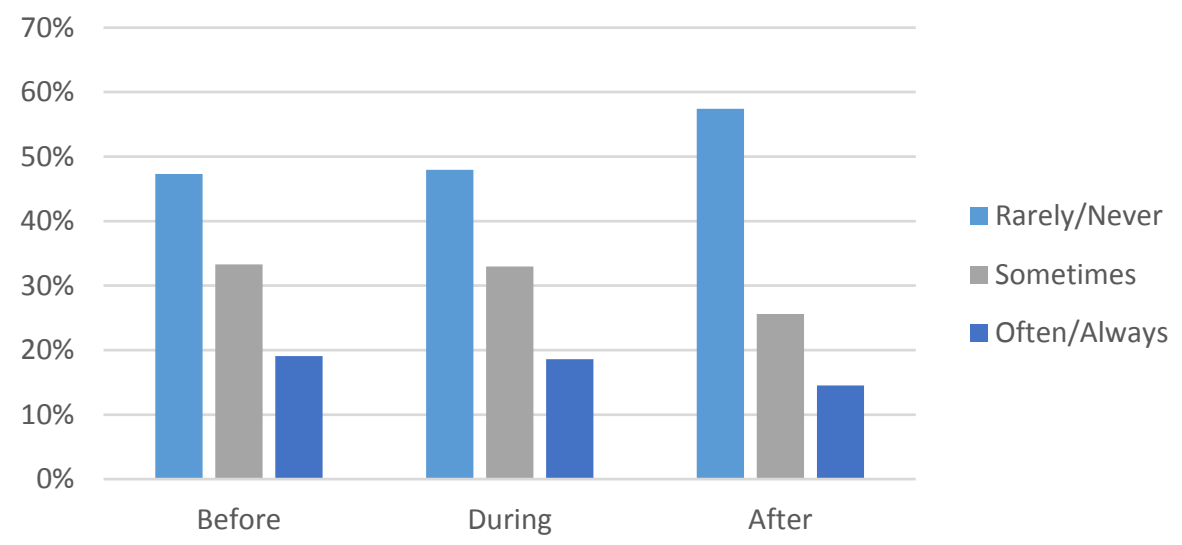

Figure 11. Self-Consciousness Before, During and After Study Abroad 
As shown in Figure 12, the data also reveal an interesting trend when student alcohol use while abroad is broken down by region. While participants reporting frequent alcohol use while abroad overall was around 30\%, there were some marked regional differences. While alcohol use during study abroad was higher than the overall average in Europe and Oceania $37.27 \%$ and $33.33 \%$ reporting frequent alcohol use, respectively), it was significantly lower in Asia (16.33\%) and Africa/Middle East $(12.36 \%)$. This is consistent both with the cultural norms surrounding drinking in those regions, as well as with Pedersen, LaBrie and Hummer's findings (2009) on foreign student drinking in cultures with high vs. low tolerance for alcohol use. It is likely that other symptoms, behaviors and experiences would differ when filtered by region, as well.

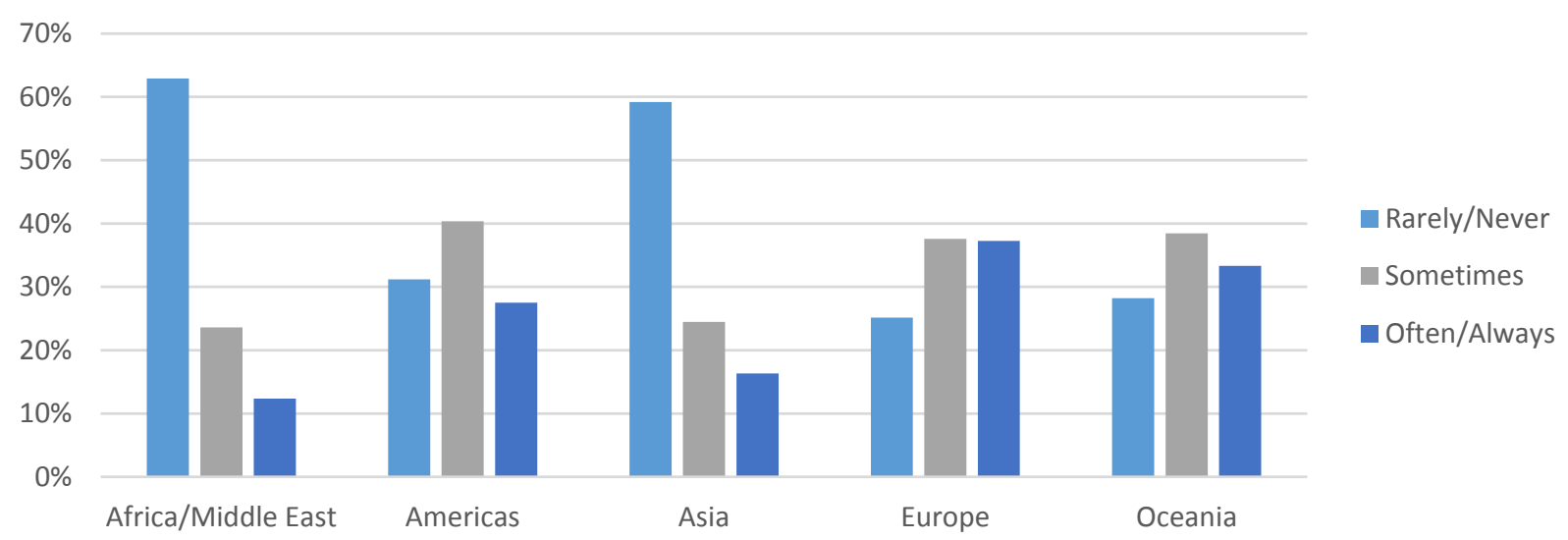

Figure 12. Student Alcohol Use During Study Abroad By Region

\section{Incidence of Student Mental Health Concerns While Abroad}

While $27.7 \%$ of respondents reported experiencing a mental health issue before going abroadconsistent with the National Alliance on Mental Health's estimate that $25 \%$ of young adults between 18-24 have a diagnosable mental health condition-only $8.3 \%$ of respondents reported experiencing a mental health condition while abroad. This may be due to the relatively short time students spent abroad or the elation many students feel at being abroad. Of the $27.7 \%$ of students who reported experiencing a mental health issue prior to study abroad, 55\% reported not disclosing this information to the program. This presents a problem, as 47 of the 51 students $(92.16 \%)$ who reported experiencing an issue onsite also reported having an issue before going abroad. We can therefore conclude that having previously experienced a mental health condition was a very strong predictor of an issue occurring abroad. We as international educators can do much more to help a student with a potential issue if we know ahead of time that there may be an issue and can prepare, and help the student prepare, for that possibility.

Nature of Diagnosed Mental Health Conditions.

Anxiety and depression were by far the most commonly cited conditions. Obsessive Compulsive Disorder, eating disorders, Bipolar Disorder, PTSD, Personality Disorder, Panic Disorder and ADHD were also cited. 
Relapse/Recurrence of Existing Conditions While Abroad.

Of the 170 students who reported experiencing a mental health issue before going abroad, only $47(27.65 \%)$ reported experiencing an issue onsite. Whether the issue onsite was the same issue as before going abroad, and whether it was a relapse or ongoing issue, is not clear.

Treatment While Abroad.

For the purposes of this study, "treatment" was not specifically defined, but rather left open to the interpretation. Treatment could, therefore, include medication, therapy/counseling, or whatever the students themselves consider as treatment for their own condition(s).

Of the $8.3 \%$ of students who reported experiencing a mental health issue while abroad, $91.8 \%$ reported NOT seeking treatment while abroad.

Of the $27.7 \%$ of students who reported experiencing a mental health condition prior to studying abroad, 55.9\% reported receiving treatment for that condition prior to going abroad. Of that 55.9\%, $70.53 \%$ reported continuing treatment while abroad. When asked why they chose not to continue treatment while abroad, students gave reasons such as "It wasn't serious enough for me to go to the trouble of making arrangements for treatment abroad," "I didn't think that there would be access to treatment on site," "I didn't trust any psychologists in India because of the way people in general viewed mental health," "it wasn't that long of a trip," and simply, "it was not necessary."

\section{Local Attitude Toward Mental Health Conditions}

Due to a faulty question ("If you shared your experience with anyone in your host country (host family, local friends, doctors, teachers, etc.), please describe your experience"), we were not able to get an accurate picture of how host nationals responded to student mental health concerns. While some students reported reactions that were somewhat indicative of local attitudes, it seems that many students interpreted "your experience" as their experience abroad in general, and answered accordingly.

\section{Summary}

This research was designed to paint an overall picture of student mental health while abroad and provide statistics on the percentage of students who report experiencing a diagnosed mental health condition before or during study abroad, the nature of these diagnosed mental health conditions, the percentage of students who disclosed pre-existing mental health concerns to program providers, the frequency of relapse/recurrence of pre-existing conditions while abroad, and frequency and type of treatment received. We also hoped to gain insight into local attitudes toward mental health conditions, but due to a faulty question, we were unable to achieve this goal.

Given the low response rate and the fact that all the data was self-reported and dealing with events that took place one to three years in the past, further research is required. The subject would, in particular, benefit from longitudinal study, rather than self-reported data on events that happened one to three years in the past.

The data from this survey could be broken down and cross-referenced in a variety of ways that perhaps might provide additional insights. This could include filtering the results by program length, in order to investigate the assumption that students on longer term programs would likely experience 
increased stress and more mental health concerns than those on short-term programs; by region, to examine the idea that perhaps students going to places that are "more different" from the U.S., such as Africa and Asia, might experience increased stress when compared to those going to "Western" English-speaking countries like Australia or the UK; or by the student's year in school, positing that perhaps older students have an easier time adjusting than younger students who may have less experience being on their own.

Furthermore, the present study does not address language issues, and it certainly stands to reason that students studying in locations where the local language is other than English (or the student's native language) would experience increased stress as compared to those studying in an Englishspeaking country. The research on international students certainly supports that premise; it would be interesting to investigate whether this is the case with U.S. students as well. Such research would also need to take into account whether the student was taking coursework in English and using the local language outside of the classroom setting (for example, a study center program offering Englishtaught courses in France) or using the local language in the classroom as well.

The current research was useful for providing general insight into student mental health while studying abroad. These findings serve as reassurance that overall, students are maintaining good mental health while abroad. While the theory that going abroad may actually lead to improved mental health upon return as a result of coping skills, confidence, problem solving skills, and independence gained while abroad certainly requires further study, it is an encouraging avenue that could have great impact on the way we talk about, promote and recruit for study abroad in the future.

\section{Acknowledgments}

The authors would like to thank the other members of the research team, Matthew Hanson and Mark J. Groberski, of the University of Minnesota-Twin Cities University Counseling and Consulting Services.

\section{References}

Austell, D., Boguslav, D., Burak, P., Hannigan, T., Reilly, R., \& Young, N. (2001). "Mental Health Issues of Students Who Cross Borders." Crisis Management in a Cross-Cultural Setting. In P. Burak \& W. Hoffa (Eds.). Washington, DC: NAFSA, 57-89.

American College Health Association (2015). "American College Health Association-National College Health Assessment II: Reference Group Executive Summary Spring 2015.” Hanover, MD: American College Health Association. Retrieved from http://www.achancha.org/reports ACHA-NCHAII.html

Burak, P. \& Hoffa, W., eds. (2001). Crisis Management in a Cross-Cultural Setting. (Washington, DC: NAFSA).

The Center for Global Education: An International Resource Center (n.d.). "Maintaining Strong Mental and Emotional Health." Retrieved from http://globaled.us/peacecorps/maintainingstrong-mental-and-emotional-health.asp

The Healthy Minds Network for Research on Adolescent and Young Adult Mental Health (2014). "Co-Occurring Mood and Alcohol Use Disorders in College Populations." Research Brief 6, 1. Retrieved from http://healthymindsnetwork.org/research/research-briefs 
Hummer, J. F., Pederson E. R., Mirza, T., LaBrie, J. W. (2010). "Factors associated with general and sexual alcohol-related consequences: an examination of college students studying abroad." Journal of Student Affairs Research and Practice, 47(4), 427-444.

Hunley, H. A. (2009). "Students' functioning while studying abroad: the impact of psychological distress and loneliness." International Journal of Intercultural Relations, 34, 386-392. doi: 10.1016/j.ijintrel.2009.08.005

Jed Foundation (n.d.). "Depression and Suicidal Behaviors in Students Studying Abroad: Identifying Students at Risk." Retrieved from https://jedfoundation.org/programs/study-abroad

Kopta, S. M. \& Lowry, J. L. (2002). "Psychometric evaluation of the Behavioral Health Questionnaire20: a brief instrument for assessing global mental health and the three phases of psychotherapy outcome." Psychotherapy Research, 12, 413-426.

Mobility International USA (n.d.). "Mental Health Considerations for International Exchange Participants." Retrieved from http://www.miusa.org/ncde/tipsheets/mentalhealth

Moores, L. \& Popadiuk, N. (2011). "Positive aspects of international student transitions: a qualitative inquiry.” Journal of College Student Development, 52(3), 291-306. doi: 10.1353/csd.2011.0040

National Alliance on Mental Illness (n.d.). "Learn About the Issue: Mental Health Issues Are Prevalent on College Campuses." Retrieved from http://www2.nami.org/Content/NavigationMenu/Find_Support/NAMI_on_Campus1/Learn _About_The_Issue/Learn_About_The_Issue.htm

Pedersen, E. R., LaBrie, J. W., \& Hummer, J. F. (2009). "Perceived behavioral alcohol norms predict drinking for college students while studying abroad." Journal of Studies on Alcohol and Drugs, 70(6), 924-928.

Pedersen, E. R., LaBrie, J. W., Hummer, J. F., Larimer, M. E., and Lee, C. M. (2010). "Heavier drinking American college students may self-select into study abroad programs: An examination of sex and ethnic differences within a high-risk group." Addictive Behaviors, 35, 844-847.

Pedrelli, P., Borsari, B., Palm, K. M., Dalton, E., Fava, M. (2013). "Combined MI + CBT for depressive symptoms and binge drinking among young adults: two case studies." Journal of Cognitive Psychology, 27(3), 235-257.

Sam, D. L. \& Eide, R. (1991). "Survey of Mental Health of Foreign Students." Scandinavian Journal of Psychology, 32, 22-30.

Sümer, S., Poyrazli, S., \& Grahame, K. (2008). "Predictors of depression and anxiety among international students." Journal of Counseling and Development, 86(4), 429-437. Doi: 10.1002/j.15566678.2008.tb00531.x 